\section{Cycle Sequencing}

\section{Keith Kretz, Walter Callen, and Valerie Hedden}

Stratagene Cloning Systems, La Jolla, California 92037
The PCR technique has revolutionized the way research is performed. PCR is being used in an ever increasing number of new techniques. One related technique that has emerged is cycle sequencing, or linear amplification sequencing, as it is sometimes known. ${ }^{(1,2)}$ Cycle sequencing utilizes a thermostable DNA polymerase and dideoxynucleotide triphosphates to generate chain-termination sequence with a temperature-cycling format (Fig. 1). There are two basic differences between cycle sequencing and PCR amplification. The first is the presence of only one primer in the cycle-sequencing reaction used to prime synthesis of one strand of the DNA. The second difference is the presence of dideoxynucleotide triphosphates in the sequencing reactions that create the base-specific terminations required. The result of the temperature cycling is linear amplification of the sequencing product leading to an increase in the signal generated during the sequencing reaction when compared with standard sequencing protocols. Cycling the sequencing reactions results in several advantages: (1) The amount of template necessary for the sequencing reaction is greatly reduced; (2) because smaller amounts of template are added, fewer impurities are introduced, meaning less template preparation is required; and (3) the high temperature at which the sequencing reactions are run and the multiple heat-denaturation steps allow doublestranded templates such as plasmids, cosmids, $\lambda$ DNA, and PCR products to be sequenced reliably without a separate denaturation step.

\section{SEQUENCING TEMPLATES}

Cycle sequencing enables researchers to sequence much smaller amounts of DNA with little or no purification. It should be noted that the purity of the template will affect the quality of the sequence data. Previously inconsistent DNA templates such as PCR products, cosmids, and $\lambda$ DNA can now be sequenced routinely using standard laboratory techniques.

Plasmids purified by any standard small- or large-scale protocol ${ }^{(3)}$ are suitable templates. Typically, 50-200 fmoles of plasmid (100-400 ng of a 3-kb plasmid) are used in the sequencing reactions; however, 1-500 fmoles of

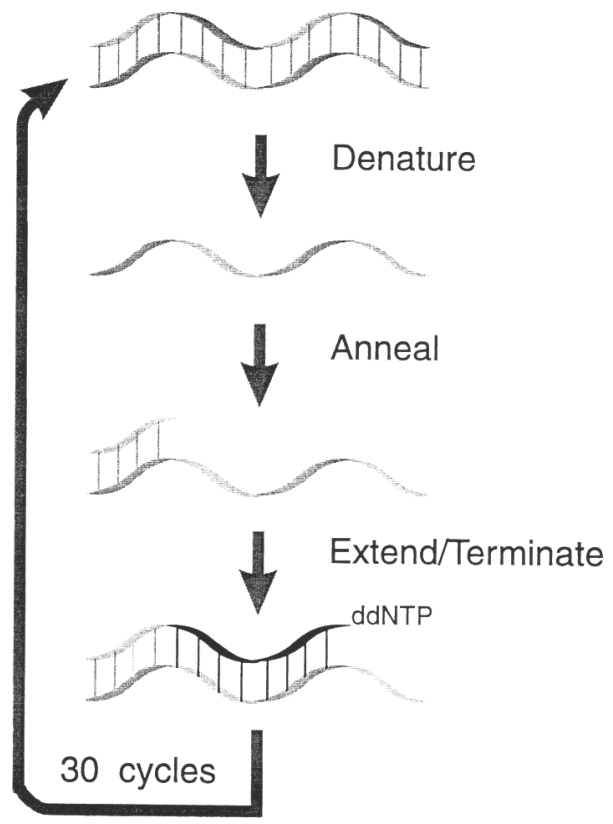

FIGURE 1 Outline of the cycle sequencing reaction. Double- or single-stranded templates are cycled through a three-temperature cycling reaction consisting of high-temperature denaturation, primer annealing, and primer extension/termination. 
plasmid template have been used successfully. Alternatively, high-copy-number plasmids may be sequenced directly from colonies using the following protocol (Fig. 2). ${ }^{(4)}$

1. The colony is picked from the plate and boiled in $25 \mu$ l of TE ( $5 \mathrm{mM}$ Tris- $\mathrm{HCl}$ at $\mathrm{pH} 8.0,0.1 \mathrm{~mm}$ EDTA) for $5 \mathrm{~min}$.

2. After vortexing well and cooling on ice, the cell debris is removed by centrifugation for $1 \mathrm{~min}$.

3. $10 \mu \mathrm{l}$ of the supernatant is used as the template in subsequent sequencing reactions.

4. This protocol requires the use of ${ }^{32} \mathrm{P}$ for an overnight exposure or a 2 - to 3-day exposure with ${ }^{33} \mathrm{P}$.

If the plasmid is present in low copy number, a 1-ml overnight liquid culture may be prepared. The cells are collected by centrifugation for $1 \mathrm{~min}$ and resuspended in $25 \mu \mathrm{l}$ of TE. The resuspended cells are then boiled and prepared as described above. Although the use of plasmid DNA obtained by boiling cells in this manner will not be of the highest quality (150-200 bases of readable sequence), the technique is particularly useful when screening large numbers of site-specific mutagenesis products or screening cloning products (K. Kretz, W. Callen, and V. Hedden, unpubl.).

M13, cosmids, and $\lambda$ DNA prepared by standard protocols ${ }^{(3)}$ are also suitable templates (Fig. 2). For M13 and $\lambda$ DNA, 10-100 fmoles should be used as template, whereas 50-200 fmoles of cosmid should be used. The DNA present in M13 or $\lambda$ plaques may be sequenced directly in a manner analogous to that for plasmids from colonies (Fig. 2). ${ }^{(4)}$

1. Cut closely around the plaque of interest with a scalpel and peel off just the top agarose layer.

2. Boil the top agarose containing the plaque in $25 \mu \mathrm{l}$ of TE for $5 \mathrm{~min}$.

3. After vortexing well and cooling on ice, any remaining pieces of agarose are removed by centrifugation for $1 \mathrm{~min}$.

4. $10 \mu \mathrm{l}$ of the supernatant is used as the template in subsequent sequencing reactions.

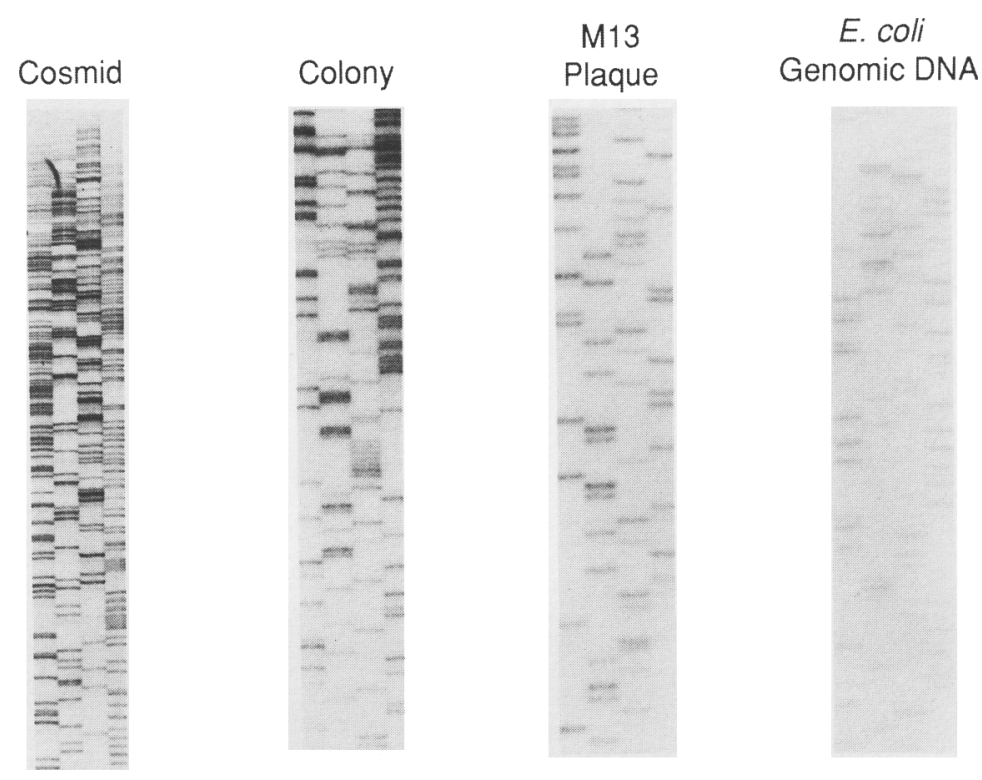

FICURE 2 Examples of nonstandard templates sequenced with the protocol detailed in the text. Cosmid DNA, plasmid DNA directly from a colony, M13 DNA directly from a plaque, and unfractionated, high-molecular-weight $E$. coli genomic DNA were sequenced using the protocols outlined in the text. 
5. This protocol requires the use of ${ }^{32} \mathrm{P}$ for an overnight exposure or a 1- to 3-day exposure with ${ }^{33} \mathrm{P}$.

When PCR products are used as the template, $0.1-1 \mu$ l of PCR product may often be used directly if the amplification yielded a single product. Note that it is very easy to overload the sequencing reaction with a short PCR product. Whenever possible, quantitate the PCR product and use 10-100 fmoles in the reaction to reduce background problems. If the sequence obtained using unpurified PCR template has an unacceptably high background, unused amplification primers and nucleotides may be removed by gel purification, purification on a glass matrix, or by selective precipitation of the PCR product as follows:

1. Mix an aliquot of the PCR reaction with an equal volume of $5 \mathrm{M}$ ammonium acetate.

2. Add an equal volume (PCR reaction plus ammonium acetate) isopropyl alcohol at room temperature.

3. Incubate at room temperature for $10 \mathrm{~min}$.

4. Microcentrifuge for $15 \mathrm{~min}$.

5. Remove the isopropyl alcohol supernatant and resuspend the pellet (usually invisible) in water or TE to a volume equal to the original PCR volume.

6. Use an appropriate amount as template.

If nonspecific bands or primer-dimer artifacts are present when an aliquot of the PCR reaction is analyzed on an agarose gel, the band of interest must be gel-isolated. These products may be recovered from the gel by a number of methods, including glass matrix extraction, enzymatic digestion of the agarose, ${ }^{(5)}$ or a modified freeze-squeeze protocol. ${ }^{(6)}$ High-quality sequence data may also be obtained by adding a portion of a band isolated in low-melting temperature agarose directly to the sequencing mixture after melting at $65^{\circ} \mathrm{C}$ for $5 \mathrm{~min} .^{(7,8)}$

In an attempt to determine the upper limit for size of the sequencing template, unfractionated, high-molecular-weight Escherichia coli genomic DNA was used as the template in a cycle sequencing reaction. Useful sequence information for 100-150 bases was obtained from this reaction. Additional experiments showed that this is not yet a reliable technique, ${ }^{(9)}$ but it does indicate that further improvements in cycle sequencing will result in the ability to sequence much larger templates. This would greatly reduce the amount of effort required to complete large-scale sequencing projects.

\section{DETECTION}

Cycle sequencing products can be labeled in a number of different ways. If radioactive labeling is used, either incorporation of an $\alpha$-labeled dNTP or end-labeled primers can be used. ${ }^{32} \mathrm{P}$ and ${ }^{35} \mathrm{~S}$ are the most common radiolabels used in sequencing. ${ }^{32} \mathrm{P}$ has the advantage of stronger signal strength, but ${ }^{35} \mathrm{~S}$ has the advantage of sharper bands and longer half-life. One disadvantage to the use of ${ }^{35} \mathrm{~S}$ in cycle sequencing is the low labeling efficiency obtained using Taq DNA polymerase. For those who wish to use ${ }^{35} \mathrm{~S}$, a non-Thermus sp. DNA polymerase-based kit is better. Recently, an exonuclease-deficient DNA polymerase from Pyrococcus furiosis was shown to be nondiscriminatory for thionucleotides providing much stronger signals. (Fig. 3). ${ }^{(10)}$ Additionally, ${ }^{33} \mathrm{P}$ was recently introduced as an alternative radioactive label for molecular biology use. ${ }^{(11,12)}$ This new label has physical characteristics intermediate between ${ }^{35} \mathrm{~S}$ and ${ }^{32} \mathrm{P}$, making it ideal for DNA sequencing applications. It gives strong, sharp bands allowing long read lengths with shorter exposure times, often $2 \mathrm{hr}$. In addition, this isotope is used efficiently by Taq DNA polymerase. 


\section{Taq}

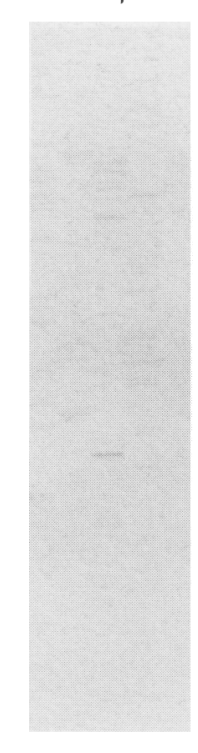

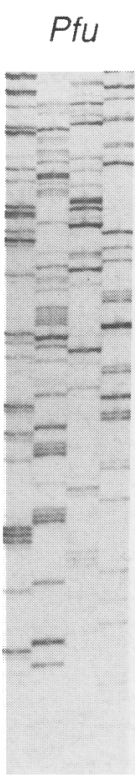

FIGURE 3 Cycle sequencing using an exonuclease-deficient DNA polymerase from Pyrococcus furiosis or Taq DNA polymerase and ${ }^{35}$ S]dATP. Pfu polymerase does not discriminate against thionucleotides.

For nonradioactive detection, hapten-labeled primers can be used and detection is accomplished enzymatically. If a biotinylated oligonucleotide is used as the sequencing primer, the sequencing products are transferred to a nylon or nitrocellulose membrane by capillary action or electroblotting. After washing and blocking the membrane, a streptavidin-alkaline phosphatase (or horseradish peroxidase) conjugate is applied. This enzyme then generates either chemiluminescent or colored products from specialized substrates.

Cycle sequencing has also been used in automated sequencing procedures. Fluorescent labels are attached to either the primers (dye primers) or dideoxynucleotide terminators (dye terminators). These labels are then excited by a laser as they pass a detector near the bottom of the gel during electrophoresis.

Commercial kits are available to perform all of these protocols.

\section{PROTOCOL (FOR Taq DNA POLYMERASE)}

1. Add $3 \mu \mathrm{l}$ of the appropriate ddNTP to each of four termination tubes. Cap the tubes and keep on ice.

2. For each DNA template, combine the following reaction components on ice and mix gently but thoroughly by pipetting:

template

primer (2-5 pmoles; $10-25$ ng of a $17-$ mer)

$4 \mu \mathrm{l} 10 \times$ sequencing buffer

$10 \mu \mathrm{Ci}\left[\alpha-{ }^{32} \mathrm{P}\right] \mathrm{dATP},\left[\alpha-{ }^{33} \mathrm{P}\right] \mathrm{dATP}$, or $\left[\alpha^{-35} \mathrm{~S}\right] \mathrm{dATP}$ (not necessary if la-

beled primers are used)

2-5 units of Taq DNA polymerase

water to a final volume of $30 \mu \mathrm{l}$

3. Aliquot $7 \mu \mathrm{l}$ of the reaction mixture from step 2 into each of the four termination tubes from step 1.

4. Overlay the reactions with $15 \mu$ l of silicone oil or mineral oil if necessary.

5. Optimum cycling parameters will vary depending on template, primer, and thermocycler used. A useful starting profile is given below:

30 cycles each of

$95^{\circ} \mathrm{C}$ for $30 \mathrm{sec}$

$60^{\circ} \mathrm{C}$ for $30 \mathrm{sec}$

$72^{\circ} \mathrm{C}$ for $60 \mathrm{sec}$ 
6. Add $5 \mu$ l of stop dye below the oil overlay and mix by pipetting.

7. Heat-denature the samples at $\geqslant 80^{\circ} \mathrm{C}$ for $2-5 \mathrm{~min}$ immediately prior to loading 1-3 $\mu$ l onto a sequencing gel.

\section{SOLUTIONS}

$10 \times$ sequencing buffer

$100 \mathrm{mM}$ Tris- $\mathrm{HCl}(\mathrm{pH} \mathrm{8.8)}$

$500 \mathrm{mM} \mathrm{KCl}$

$40 \mathrm{mM} \mathrm{MgCl}_{2}$

$0.01 \%$ gelatin

$20 \mu \mathrm{M}$ dATP

$50 \mu \mathrm{M}$ dCTP

$50 \mu \mathrm{M}$ dGTP

$50 \mu \mathrm{M}$ dTTP

Termination mixes

ddATP $(600 \mu \mathrm{M})$

ddCTP $(600 \mu \mathrm{M})$

ddGTP $(100 \mu \mathrm{M})$

Stop dye

ddTTP $(1000 \mu \mathrm{M})$

$95 \%$ formamide

20mM EDTA

$0.05 \%$ bromophenol blue

$0.05 \%$ xylene cyanol

\section{CONCLUSIONS}

The traditional sequencing templates (purified M13 and plasmids) are excellent templates for cycle sequencing, but the use of the temperature-cycling format now makes sequencing of PCR products, cosmids, and $\lambda$ DNA routine as well. In addition, it has been demonstrated that plasmid DNA from colonies and phage DNA from plaques are also potential sequencing templates. Future improvements in this technique should allow sequence to be obtained from ever larger templates as suggested by the results obtained using $E$. coli genomic DNA (Fig. 2).

\section{ACKNOWLEDGMENTS}

We thank Dr. Mary Simcox, Eric Mathur, Brad Scott, Kirk Nielson, and Janice Cline for providing exonuclease-deficient $P f u$ DNA polymerase.

\section{REFERENCES}

1. Murray, V. 1989. Improved double-stranded DNA sequencing using the linear polymerase chain reaction. Nucleic Acids Res. 17: 8889.

2. Carothers, A.M., G. Urlaub, J. Mucha, D. Grunberger, and L.A. Chasin. 1989. Point mutation analysis in a mammalian gene: Rapid preparation of total RNA, PCR amplification of cDNA, and Taq sequencing by a novel method. BioTechniques 7: 494-499.

3. Sambrook, J., E.F. Fritsch, and T. Maniatis. 1989. Molecular cloning: A laboratory manual. Cold Spring Habor Laboratory, Cold Spring Harbor, New York.

4. Krishnan, B.R., R.W. Blakesley, and D.E. Berg. 1991. Linear amplification DNA sequencing directly from single phage plaques and bacterial colonies. Nucleic Acids Res. 19: 1153.

5. Yaphe, W. 1957. Can. J. Microbiol. 3: 987-993.

6. Hedden, V., W. Callen, and K. Kretz. 1992. Freeze-N-Spin ${ }^{\mathrm{TM}}$ filter cups for fast DNA recovery. Strategies Mol. Biol. 5: 80.

7. Kretz, K.A. (unpubl.).

8. Kretz, K.A. and J.S. O'Brien. 1993. Direct sequencing of PCR products from low-melting 
temperature agarose. Methods Enzymol. 218: 72-79.

9. Kretz, K. and W. Callen. (unpubl.).

10. Hedden, V., M. Simcox, W. Callen, B. Scott, J. Cline, K. Nielson, E. Mathur, and K. Kretz. 1992. Superior sequencing: Cyclist ${ }^{\mathrm{TM}}$ Exo $^{-}$Pfu DNA sequencing kit. Strategies Mol. Biol. 5: 79.

11. Zagursky, R.J., P.S. Conway, and M.A. Kashdan. 1991. Use of ${ }^{33} \mathrm{P}$ for Sanger DNA sequencing. BioTechniques 11: 36-38.

12. Evans, M.R. and C.A. Read. $1992 .{ }^{32} \mathrm{P},{ }^{33} \mathrm{P}$ and ${ }^{35} \mathrm{~S}$ : Selecting a label for nucleic acid analysis. Nature 358: 520-521. 


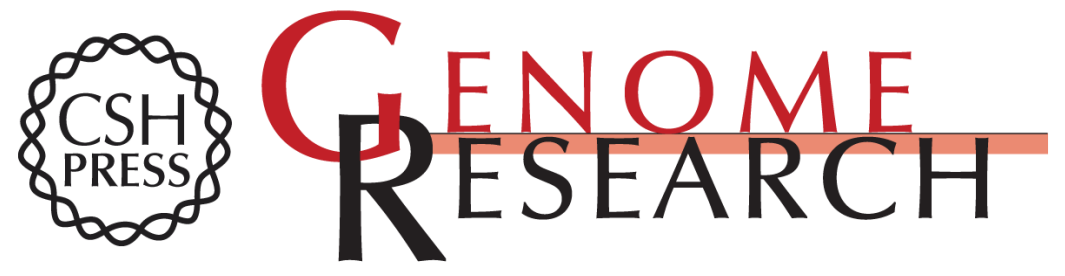

\section{Cycle sequencing.}

K Kretz, W Callen and V Hedden

Genome Res. 1994 3: S107-S112

\section{License}

Email Alerting Service

Receive free email alerts when new articles cite this article - sign up in the box at the top right corner of the article or click here.

\section{Affordable, Accurate Sequencing.}

To subscribe to Genome Research go to:

https://genome.cshlp.org/subscriptions 